Methods: The study involved 70 (52-female and 18-male) patients treated in the Department of Rheumatology and Connective Tissue Diseases. All patients fulfilled the SLICC classification criteria of SLE. $46 / 70$ pts fulfilled clinical and laboratory criteria of Antiphospholipid Syndrome (I group SLE/APS-46pts) and 24/70 pts (II group SLE/aPL $(+)-24)$-they had criteria antibodies but did not display clinical criteria symptoms of APS. In the whole study group the mean age was: $38,5 \pm 12,9$ years (range 18-71), the duration of the disease was $8,3 \pm 6,5$ years (range $0-37$ ). The presence of Ab was detected in patients' serum using the commercially available tests: aPL-immunodot assay Anti-Phospholipid 10 Dot, for the qualitative detection of IgG or IgM antibodies. Statistical data analysis was performed using Statistica v13.0

Results: In the study group of 70 patients we detected the presence of the following aPLs: a- cardiolipin IgM $-33,7 \%$, IgG $-50 \%$; a-phosphatidic acid IgM $-17,5 \%$, IgG -11,2\%; a-phosphatidylcholine $\lg M$ and $\lg G-0$; a-phosphatidylethanolamine $\lg M$ and $\lg G-0$; a-phosphatidylglycerol $\lg M-4,4 \%$, IgG $-10 \%$; aphosphatidylinositol IgM-11,2\%, IgG-10\%; a-phosphatidylserine IgM-31,2\%, IgG48,7\%; a-annexin V IgM -20\%, IgG -10\%; a-b2-GP I lgM-33,7\%, IgG-30\%; aprothrombin lgM $-51,4 \%$, IgG-30\%.

The following non-criteria clinical symptoms of APS were present: nephropathy in $27,1 \%$, hypertension- $41,1 \%$, livedo reticularis $11,4 \%$, convulsions/chorea- $5,7 \%$, thrombocytopenia- $20 \%$ of the study group.

No statistically significant differences in the frequency of occurrence of individual non-criteria aPLs, as well as non-criteria clinical symptoms of APS have been found in the examined subgroups of SLE/SAPS and SLE/aPL (+) patients.

Conclusions: The prevalence of non-criteria aPLs in SLE and APS pts is similar to pts with SLE with criteria- aPL. Non-criteria clinical symptoms of APS occured with the same frequency in pts with SLE and APS and in SLE with criteria aPL.

Disclosure of Interest: None declared

DOI: 10.1136/annrheumdis-2018-eular.7366

\section{AB0599 RELATION BETWEEN THE DEFICIT/DEFICIENCY OF VITAMIN D AND THE DEPRESSION/ANXIETY IN PATIENTS WITH LUPUS IN THE DEPARTMENT OF RHEUMATOLOGY OF THE HOSPITAL OF CLINICS}

M.A. Vazquez ${ }^{1}$, N. Ortiz ${ }^{1}$, V. Martínez ${ }^{1}$, L. Roman ${ }^{1}$, K. Bauman ${ }^{1}$, M. Melo ${ }^{1}$ E. Acosta ${ }^{2}$, M. Duarte 1 , I. Acosta Colman ${ }^{1} .{ }^{1}$ Central, Hospital de Clínicas San Lorenzo; ${ }^{2}$ Central, Instituto de Investigación en Ciencias de la Salud San Lorenzo, Asunción, Paraguay

Background: It has been postulated that low concentrations of 25-hidroxivitamin D serum [25 $(\mathrm{OH}) \mathrm{D}]$ is associated with a greater prevalence of depression. People with deficient levels of vitamin $D$ are more likely to experience mood disorders such as depression and anxiety. The vitamin D plays a role in the release of neurotransmitters such as serotonin and dopamine which is why is interesting the study of this in patients with systemic lupus erythematosus, who are discouraged from sun exposure.

Objectives: Determine the association between the deficit/insufficiency of vitamin D and the anxiety/depression in patients with SLE of the Department of Rheu matology of the Hospital de Clínicas

Methods: Observational study of longitudinal court based in a questionnaire according to the scale HADS (Hospital anxiety and Depression Scale) and the dosages of vitamin D performed on patients who entered the LUPUS PY cohort with prior informed consent. The dosage of vitamin $D$ realised by chemiluminescence. Data and samples were taken in week 0 and week 24 and the prevalence of depression and anxiety and its association with vitamin $D$ deficiency and insufficiency were identified. Patients with vitamin D deficiency or insufficiency were supplemented with vitamin D. For the descriptive analysis of the quantitative variables, average and SD were used, for the qualitative frequencies and percentages. For the analysis of association the test $\times 2$ was used. The value of the $p$ considered statistically significant was less than 0,05 .

Results: In relation to the characteristics of the studied cohort, we can see that $90.5 \%$ were female, with an average age of $33 \pm 10.2$ years. At week 0 the average value of vitamin D concentration was $31.8 \pm 10.2 \mathrm{ng} / \mathrm{ml}$. It is found that $4,48 \%$ of patients had depression and $33,69 \%$ of patients have anxiety. In the week 24 the value of the average of vitamin D was of $31,1 \pm 13,6 \mathrm{ng} / \mathrm{ml}$. It was observed in this week that $6 \%$ of patients presented depression and $12 \%$ of patients anxiety. In the analysis of association there was no association between vitamin $D$ deficits and the presence of depression or anxiety of these patients both at the week 0 as a week 24 post vitamin D supplementation such, and as seen in table 1.
Abstract AB0599 - Table 1. Deficit and insufficiency of vitamin D associated with the depression and anxiety in patients with SLE.

\begin{tabular}{|c|c|c|c|}
\hline & $\begin{array}{c}\text { Deficit insufficiency } \\
\text { of Vit D }\end{array}$ & Depression & P valúe \\
\hline Week 0 & $35(47,29 \%)$ & $3(4,48 \%)$ & 0,287 \\
\hline Week 24 & $33(44,59 \%)$ & $4(6 \%)$ & 0,092 \\
\hline & $\begin{array}{c}\text { Deficit } \text { insufficiency } \\
\text { of Vit D }\end{array}$ & Anxiety & P valúe \\
\hline Week 0 & $35(47,29 \%)$ & $14(33,69 \%)$ & 0,287 \\
\hline Week 24 & $33(44,59 \%)$ & $8(12 \%)$ & 0,092 \\
\hline
\end{tabular}

Conclusions: A significant percentage of patients with deficient or insufficient vitamin D were found, as well as a considerable percentage had depression or anxiety, although no association was found between the state of this vitamin and the alterations of the studied mood. More studies are required that include more patients in order to obtain more conclusive results.

\section{REFERENCE:}

[1] Okereke, Olivia I., Ankura Singh. "The Role of Vitamin D in the Prevention of Late-Life Depression." Journal of affective disorders 198 (2016): 1-14. PMC. Web. 30 Jan. 2018.

Disclosure of Interest: None declared DOI: 10.1136/annrheumdis-2018-eular.5953

\section{AB0600 RELEVANCE OF OPHTHALMOSCOPIC EVALUATION IN PATIENTS WITH SYSTEMIC LUPUS ERYTHEMATOSUS: UNDERESTIMATION OF INTRAOCULAR PRESSURE VALUES}

M.C.D.F. Salgado ${ }^{1}$, A.D.C. M. Paiva ${ }^{1}$, Y.D.F. B. Chagas $^{1}$, J.L.P. Vaz ${ }^{1}$, F.C. Freire ${ }^{1}$, L.M. Arêas ${ }^{2}$, F.C. Freire ${ }^{1}$, V. Vigneron ${ }^{1}$, Y.D.F. B. Chagas ${ }^{1}$, J.L.P. Vaz ${ }^{1}$, A. Vaz $^{1}$, V. Vigneron ${ }^{1} .{ }^{1}$ General Medicine; ${ }^{2}$ ophtalmology, Federal University of Rio de Janeiro State, Rio De Janeiro, Brazil

Background: The evaluation of the size of the optic nerve papilla in ophthalmoscopy is an important tool for the diagnosis of glaucoma in individuals who do not present elevated intraocular pressure (IOP) levels. The calibration of the IOP is performed through Goldmann's tonometry, which consists of flattening the central cornea with a tonometer. Patients with Systemic Lupus Erythematosus (SLE) have circulating autoantibodies and immunocomplexes that alter corneal biomechanics, resulting in underestimated IOP values.

Objectives: To evaluate the IOP values and the presence of increased excavation in patients with SLE, reinforcing the importance of ophthalmoscopy in this population.

Methods: Descriptive study. Analysis of IOP measurement and papillary excavation of 50 SLE patients.

Results: All patients had IOP values within the normal range $(8-21 \mathrm{mmHg})$. In a total of 100 eyes evaluated, four $(4 \%)$ had increased papillary excavation.

Conclusions: Type I collagen is essential for the maintenance of biomechanical parameters and resistance of the cornea. At the corneal level, the activation of the complement system results in the lysis of type I collagen fibres, reducing corneal thickness and resistance. Therefore, IOP values for tonometry will be reduced and underestimated. Comparing the IOP values of SLE patients and healthy volunteers, there are lower results $(p<0.001)$ in lupus patients. In the present study, no patient had IOP changes. However, $4 \%$ of the eyes revealed increased excavation. These findings reflect the results of Yazici at al, and reinforce the importance of ophthalmoscopy in the screening of glaucoma in SLE patients.

\section{REFERENCES}

[1] Silpa-archa S, Lee J, Foster CSI. Ocular manifestations in systemic lupus erythematosus. Br J Ophtalmol. 2016;100:135-41.

[2] Moreira CA, Alves MR. Semiologia Básica em Oftalmologia. 3. ed. Rio de Janeiro: Cultura Médica: Guanabara Koogan; 2013.

[3] Yazici AT, Kara N, Yüksel K, Altinkaynak H, Baz O, Bozkurt E, et al. The biomechanical properties of the cornea in patients with systemic lupus erythematosus. Eye. 2011;25:1005-9.

Disclosure of Interest: None declared

DOI: 10.1136/annrheumdis-2018-eular.7018 